\title{
Performance Impacts of Strategy, Information Technology Applications, and Business Process Outsourcing in U.S. Manufacturing Plants
}

\author{
Indranil Bardhan • Sunil Mithas• Shu Lin \\ School of Management, University of Texas at Dallas, Richardson, Texas 75083-0688, USA \\ Robert H. Smith School of Business, University of Maryland, College Park, Maryland 20742, USA \\ Craig School of Business, California State University, Fresno, California 93740-8001, USA \\ bardhan@utdallas.edu・smithas@umd.edu・shulin@csufresno.edu
}

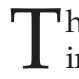

his paper develops a conceptual model to study the role of outsourcing strategies and plant-level 1 information technology (IT) application infrastructure in the outsourcing of production and support business processes, as well as their subsequent impact on overall plant performance. We validate this model empirically using cross-sectional survey data from U.S. manufacturing plants. We find that some IT applications are more effective at enabling the outsourcing of business processes than others. For example, the implementation of enterprise management systems is associated with the outsourcing of both production and support processes, whereas operations management systems are not associated with the outsourcing of plant processes. Plants with a low-cost outsourcing strategy are more likely to outsource support processes than plants with a competency-focused outsourcing strategy. However, both cost- and competency-based strategies have a positive and similar impact on the outsourcing of production processes. In terms of implications for plant performance, our findings indicate that the outsourcing of production and support processes is associated with higher gross margins. Although plant IT infrastructure is positively associated with favorable on-time delivery rates, there is no positive association between the incidence of plant outsourcing and on-time delivery rates. These results have implications for crafting plant-level outsourcing strategies and for investments in IT systems to facilitate the outsourcing of business processes for enhanced plant performance.
\end{abstract}

Key words: IT infrastructure; production process outsourcing; support process outsourcing; outsourcing strategy; profitability; plant performance; business value of information technology

Submissions and Acceptance: Submissions and Acceptance: Received October 2005, revision received October 2006, accepted January 2007 by Sunder Kekre.

\section{Introduction}

Increasing competitive intensity and globalization are forcing firms to shift from a strategy based on the ownership of assets to leveraging the capability, scale, cost, cycle time, and innovation advantage of business partners (Apte and Mason 1995; Gottfredson, Puryear, and Phillips 2005; Niezen and Weller 2006). As companies buy raw materials and components from a vast network of suppliers and locate their manufacturing plants in far-away countries, they increasingly rely on their vendors and business partners to coordinate the manufacturing and movement of goods across the value chain (The Economist 2006). Firms are realizing the importance of developing their outsourcing capabilities and enter into arrangements with vendors to handle both production processes (e.g., fabrication, assembly) and support processes (e.g., logistics, distribution, warehousing, information technology [IT], and product design). Similar to Cisco and Microsoft, many manufacturing plants outsource both production and support processes to achieve the efficiencies derived from the expertise of third-party companies 
that specialize in these business processes (Bardhan, Whitaker, and Mithas 2006).

Despite the growing importance of outsourcing and its critical role in supply chain management, few studies have empirically investigated the role of IT applications in plant process outsourcing and their subsequent impact on profitability and on-time delivery. Although previous research has investigated issues related to IT applications and IT outsourcing (Aral, Brynjolfsson, and Wu 2006; Banker et al. 2006; Choudhury, Hartzel, and Konsynski 1998; Cotteleer 2006; Cotteleer and Bendoly 2006; Dibbern et al. 2004; Hitt, Wu, and Zhou 2002; McAfee 2002; Mithas and Jones 2007; Whitaker, Mithas, and Krishnan 2007), none of these studies have investigated the role of IT applications and outsourcing strategies as they relate to the outsourcing of plant processes and plant performance.

This study poses the following research questions: (a) What is the impact of IT application infrastructure on the extent of outsourcing of production and support processes? (b) What is the role of outsourcing strategies in determining the extent of production and support outsourcing? (c) What is the subsequent impact of production and support outsourcing on profitability and on-time delivery? We develop our theoretical framework by drawing on prior research in operations management and information systems (IS) to link IT application infrastructure, process outsourcing, and plant performance. We then empirically validate our model by analyzing data for a cross-section of U.S. manufacturing plants, accounting for the role of contextual variables, such as plant characteristics and industry type.

Our work extends previous research in the supply chain management and the IS literature in two important ways (Kouvelis et al. 2006). First, ours is the first study to examine the impact of two major types of plant IT applications-enterprise management systems (EMS) and operations management systems (OMS) - on production and support outsourcing. By focusing on specific IT applications and examining their impact on both production and support outsourcing, we gain a more complete understanding of how IT systems affect plant performance. In doing so, we extend previous research that has studied the effect of aggregate IT expenditures only on production outsourcing (Bardhan, Whitaker, and Mithas 2006). This contribution complements prior research that has argued for the critical role of IT infrastructure as an enabler of organizational capabilities and organizational performance (Barua and Mukhopadhyay 2000; Brynjolfsson and Hitt 1996; Buhman, Kekre, and Singhal 2005; Kauffman and Kriebel 1988; Lucas 1993; Mithas et al. 2005b; Rai, Patnayakuni, and Seth 2006;
Sambamurthy, Bharadwaj, and Grover 2003) and focuses attention on the role of production and support outsourcing as important mediators of the relationship between IT infrastructure and plant performance.

Second, this study shows how strategic considerations affect plant outsourcing and have performance implications. In contrast with previous work that has studied the impact of generic plant-level strategies on production outsourcing and performance (Bardhan, Whitaker, and Mithas 2006), we relate a more specific dimension of plant strategy (i.e., outsourcing strategy) with the outsourcing of production and support processes and the subsequent impact on profitability and on-time delivery (Thurm 2007). This contribution responds to a recent call to broaden the operations strategy literature by understanding the role of strategies that go beyond manufacturing strategy (Boyer, Swink, and Rosenzweig 2005; Ketokivi 2006) and to understand the mechanisms that mediate the links between strategies and profitability (Rosenzweig and Roth 2004).

We organize the remaining sections as follows. In Section 2, we review the background literature and develop our research hypotheses. In Sections 3 and 4, we discuss the estimation methodology and present the results, respectively. Section 5 provides a discussion of the results and offers some concluding remarks.

\section{Background and Theory}

Several macroeconomic factors, including globalization, competitive pressures, and the need to leverage availability of the talent pool across national boundaries led to the emergence of outsourcing as an important vehicle for plants to contract their business processes to external providers to reduce costs and obtain access to specialized resources. The outsourcing of business processes in manufacturing plants involves not only procurement of products and services from external vendors but also transfer of the responsibility for the business processes and related knowledge to third parties. The information associated with these processes may involve a combination of tacit and explicit knowledge. The effective management of information processes across inter- and intra-organizational boundaries is extremely challenging as a result of several factors: volatility in customer requirements and external market conditions, lack of suitable IT infrastructure, information security, and the lack of common standards or processes to facilitate seamless knowledge transfer.

The prior literature suggests three primary reasons for the outsourcing of business processes: (a) lower costs associated with the scale economies and greater 
efficiencies provided by outsourcing vendors, (b) the transfer of risks associated with market and technological uncertainty to an external organization, and (c) access to specialized skills and resources that the client does not possess (Kakabadse and Kakabadse 2002). Outsourcing also provides firms with greater flexibility in the deployment of resources in the face of rapidly changing technologies and increasing complexity of product development (Gosain, Malhotra, and El Sawy 2005; Ketokivi 2006). Researchers argue that a network of suppliers could provide the capabilities necessary for a manufacturing plant to adjust the scale and scope of its production facilities at a lower cost in response to volatile market conditions (Quinn 1994). If firms can leverage a network of high-quality suppliers to collaborate with across the value chain, outsourcing may also be associated with a decrease in lead times (Quinn and Hilmer 1994).

Outsourcing also has several pitfalls. Poor vendor management skills may lead to a loss of management control, resulting in higher costs, loss of institutional knowledge, and the risk of becoming too dependent on vendors to perform routine operational tasks. Other risks may include the loss of flexibility due to contractual lock-in arrangements that could prevent upgrades to new technologies and a potential increase in costs (Lacity, Wilcocks, and Feeny 1995; Quinn 1994). For example, a recent study by Deloitte Consulting (2005) of 50 large IT outsourcing deals reports that $38 \%$ of respondents paid additional costs for services they believed were included in the contracts, and $44 \%$ responded that vendors did not have the capabilities to provide the expected level of quality and cost savings, resulting in participants' decisions to bring the outsourced operations back in-house.

The role of organizational IT infrastructure in facilitating the outsourcing of business processes also remains unclear. Although it might be expected that IT applications at the customer and supplier interfaces would be more effective at facilitating outsourcing than IT applications focused on managing internal business processes, none of the previous studies have specifically investigated these issues. Likewise, a firm's strategic stance is likely to be a major factor in outsourcing decisions; however, little is known about how outsourcing strategies influence the outsourcing of business processes and performance (Thurm 2007). Thus, there is a need to explore further the antecedents and impacts of outsourcing business processes.

This article focuses on the manufacturing plant level and studies the role of plant strategies and IT application infrastructure in enabling the outsourcing of plant production and support processes and their performance implications. We conceptualize plant-level IT infrastructure as the usage of different types of plant IT applications that have been implemented. Specifically, we study two classes of plant ITs: (a) OMS and (b) EMS. ${ }^{1}$ We measure the extent of outsourcing of four supporting business processes: (a) warehousing and distribution, (b) IT, (c) transportation, and (d) research and development (R\&D). We also measure the extent of outsourcing of three production processes: (a) fabrication or processing, (b) assembly, and (c) staging or packaging. Plant-level OMS and EMS applications can enable greater collaboration with partners by providing the infrastructure necessary for the assimilation and integration of information across different organizational functions.

\subsection{Hypotheses}

2.1.1. IT Infrastructure and Business Process Outsourcing. Prior research suggests that the rationale for outsourcing is to leverage the specialized capabilities of external suppliers that enable organizations to reduce costs and focus on core capabilities. This perspective is consistent with transaction cost economics arguments, which suggest that organizations attempt to minimize the sum total of production and transaction costs through their firm boundary decisions. Although the outsourcing of business processes may offer lower production costs (through access to economies of scope or specialization that vendors may enjoy), these advantages may come at the expense of higher transaction costs (costs involved in contracting with a reliable supplier, monitoring and enforcing the contract, and coordinating with the supplier). A focus on total cost minimization will lead manufacturing plants to focus on their core capabilities and outsource business processes that are not essential to core manufacturing competencies and for which vendors enjoy production cost advantages. Conversely, higher transaction costs may overwhelm the savings in production costs, which would lead firms to integrate vertically and produce internally. Thus, transaction characteristics and benefits associated with business processes, whether outsourced or managed inhouse, influence organizational boundaries.

We extend prior work by investigating how plant IT systems enable plants to outsource production and support processes. Previous research has suggested that greater usage of IT application infrastructure would lead to increased outsourcing of business processes because of reduction in coordination costs (caused by a sharp decline in IT costs, which makes it easy for partners to exchange information), transaction risk (through better monitoring of vendors), and asset specificity (Clemons, Reddi, and Row 1993; Malone, Yates, and Benjamin 1987; Wagner 2006). Recent

\footnotetext{
${ }^{1}$ We define these classes of IT applications in the "Variable Definition" section.
} 
research has suggested that IT systems also facilitate the disaggregation and outsourcing of business processes through their impact on codifiability, standardizability, and modularizability (Mithas and Whitaker 2007). We contextualize these arguments at the plant level to propose our hypotheses.

Plant OMS facilitate greater control of plant operations by supporting the deployment and allocation of plant assets and coordination of these assets across multiple factories. In line with the typology of IT resources that Wade and Hulland (2004) propose, OMS represent inside-out IT resources that are focused on enhancing the capabilities of internal plant operations by supporting cost-effective operations. Warehousing and transportation management systems enable plants to support their distribution network and ensure that processes that support core production activities are managed centrally. Thus, we hypothesize that the implementation of OMS will be associated with a greater propensity to outsource supporting processes, such as transportation, warehousing, and IT activities.

Similarly, implementation of EMS, such as design systems and resource-planning software, provides the IT infrastructure that enables plant design teams to improve the overall efficiency of information processing as a result of faster information exchanges with their outsourcing partners (Banker et al. 2006). Such systems also improve the speed of execution of product design tasks, such as design iterations, and enables greater concurrency in executing tasks with suppliers and partners (Bardhan 2007). In our study, EMS applications include both spanning and outside-in types of IT resources, which provide interorganizational capabilities for making joint decisions with business partners, such as customers and suppliers, and fostering supplier involvement in order management and logistics processes (Mithas, Krishnan, and Fornell 2005a; Mukhopadhyay and Kekre 2002; Ramasubbu, Mithas, and Krishnan 2008; Srinivasan, Kekre, and Mukhopadhyay 1994). For example, electronic data interchange and radio frequency identification device (RFID) applications enable firms to work with an extended enterprise network of suppliers and partners and foster capabilities for quick response and flexibility to deal with market volatility (Ross, Beath, and Goodhue 1996; Whitaker, Mithas, and Krishnan 2007; Zaheer and Zaheer 1997). Thus,

Hypothesis 1. Plants with greater levels of (a) OMS usage and (b) EMS usage are more likely to outsource their supporting processes.

OMS applications also facilitate the outsourcing of production activities by enabling firms to implement collaborative manufacturing capabilities in which pro- cess workflows are coordinated centrally to provide managers with real-time tracking, visibility, and control capabilities. For example, manufacturing execution systems allow plant personnel to share product data specifications with partners while maintaining revision control necessary for monitoring work performed by outsourcing vendors (Banker et al. 2006). Similarly, EMS applications, such as enterprise resource planning, material resource planning, and financial-planning systems, also facilitate production outsourcing by providing resource-planning and scheduling capabilities necessary to coordinate external processes managed by vendors with internal plant operations. For example, changes in customer demand may require plant ERP applications to share updated data with their outsourcing partners so that appropriate changes to production schedules can be implemented rapidly. Thus,

Hypothesis 2. Plants with greater levels of (a) OMS usage and (b) EMS usage are more likely to outsource production processes.

2.1.2. Outsourcing Strategy and Business Process Outsourcing. We draw on previous research that argues that most firms follow a primary strategy or value discipline (e.g., cost leadership, differentiation, focus) to derive implications for an outsourcing strategy (Miles et al. 1978; Porter 1996). Because natural tensions exist between primary generic strategies, most firms follow one of two types of outsourcing strategies: cost-reduction or competency-based differentiation (Rust, Moorman, and Dickson 2002). Some firms focus on a cost leadership strategy by using outsourcing as a means to achieve a lower cost structure. For example, a recent study of 50 large outsourcing deals by Deloitte Consulting (2005) indicates that $70 \%$ of respondents were motivated primarily by "cost savings" as their reason for outsourcing. Cost-focused strategies are based on the assumption that external vendors provide greater operating efficiency as a result of several factors, including economies of scale, greater process expertise, and cost avoidance related to significant capital expenditures that outsourcers have already made.

Another perspective on outsourcing strategy draws on the knowledge-based theory of the firm, which posits that outsourcing agreements attempt to leverage suppliers' skills and competencies (Engardio et al. 2005; Grant 1996; Kogut and Zander 1996). Knowledge-based theory emphasizes the importance of exploiting knowledge resources within and outside organizational boundaries to access the unique competencies the outsourcer offers that may be available in the form of relevant skills, technological resources, and additional capacity (Grant and Baden-Fuller 
2004). In an outsourcing context, this theoretical perspective suggests that outsourcing to external suppliers enables firms to leverage vendors' complementary skills and resources. Thus, the managerial choice to outsource a business process may be driven by the need to access specialized skills, technologies, capacity, or human resources that are not readily available within firm boundaries. In such situations, firms pursue strategies that focus on "competency-based differentiation," and outsourcing decisions are made depending on external access to specialized competencies.

Our perspective on the motivation for outsourcing in manufacturing environments is consistent with the calls to broaden the scope of operations strategies in a survey of the prior operations literature (Boyer, Swink, and Rosenzweig 2005). For example, research on strategic sourcing in manufacturing firms indicates that firms emphasize manufacturing and design flexibility and product variety in their selection of appropriate sourcing strategies (Narasimhan and Das 1999). Although overall manufacturing cost remains an important area of attention, plant mangers also want to enhance manufacturing flexibility and develop quick response capabilities to deal with any risks from disruption in supply chains (Hendricks and Singhal 2005; Kleindorfer and Saad 2005). Early involvement in and the incorporation of supplier competencies into product development and logistics can also enhance supply chain flexibility and improve the chances of outsourcing success. On the basis of these arguments, we posit that both cost reduction and external competencybased strategies may be associated with the outsourcing of business processes.

Hypothesis 3. Plants with (a) cost-focused outsourcing strategies and (b) strategies that focus on competencydriven differentiation are more likely to outsource production and support business processes.

2.1.3. Outsourcing and Plant Performance. The outsourcing of supporting and production business processes is likely to confer several advantages to manufacturing plants and has implications for plant performance. We assess plant performance with two measures: gross margins and on-time delivery rate. Gross margins represents a measure of overall plantlevel financial performance that is indicative of the overall operational and financial health of the plant (Narasimhan and Das 1999). On-time delivery rate is indicative of the effectiveness of the plant's operational performance and represents a quality-related dimension of plant operational performance; percentage of on-time delivery can be considered a reasonable proxy for plant quality (compared with the financial picture alone).
Next, we discuss the advantages of outsourcing supporting processes. First, by outsourcing support activities to external providers, plants can focus more on their core competencies and delegate the execution of support activities to other providers that specialize in the management of such processes, such as IT or logistics outsourcing (Dess et al. 1995). Second, support process outsourcing may enable plants to allocate their resources optimally in plant resources and equipment that are critical for production (Bettis, Bradley, and Hamel 1992). Third, the outsourcing of support activities may be associated with better operational performance because of the potential for efficiency gains that can be attributed to the specialized expertise and competencies that external partners provide. Thus, we hypothesize that the outsourcing of support activities is associated with improved plant performance.

Outsourcing of production processes may also be associated with improvements in plant performance. Production outsourcing is an important option for plants because they can contract their production processes to achieve greater manufacturing flexibility by gaining access to specialized resources when market conditions require changes in plant product mix or volume. It allows plants to quickly ramp up production (or ramp down) in response to volatility in customer demand and mitigate risks posed by demand uncertainty to third-party contractors. While firms may outsource manufacturing processes to expand production capacity or focus on their core competencies, the outsourcing of production processes has also been associated with lower costs and greater product quality (Bardhan, Whitaker, and Mithas 2006). Thus, we hypothesize that plants that outsource production processes are more likely to realize greater levels of manufacturing performance.

Hypothesis 4. The outsourcing of plant (a) support processes and (b) production processes is associated with higher gross margins.

HyротHESIs 5. The outsourcing of plant (a) support processes and $(b)$ production processes is associated with favorable on-time delivery rates.

\section{Method}

The data for this research come from the IndustryWeek-Manufacturing Performance Institute (MPI) Census of Manufacturers 2003 survey of U.S. manufacturing plants. The survey was electronically mailed to plant managers and controllers from MPI's database of manufacturing plants. The Web-based online survey collected information about plant IS, outsourcing strategies, the extent of business process outsourc- 


\begin{tabular}{|c|c|c|c|}
\hline NAICS Code & Industry Sector & Percentage of Sample ${ }^{1}$ & Percentage of U.S. Manufacturers ${ }^{2}$ \\
\hline 311 & Food & 4.31 & 7.66 \\
\hline 312 & Beverage and tobacco products & 0.43 & 0.87 \\
\hline 313 & Textile mills & 1.4 & 1.14 \\
\hline 314 & Textile products & 0.22 & 2.13 \\
\hline 315 & Apparel & 0.86 & 3.64 \\
\hline 316 & Leather and allied products & 0.11 & 0.44 \\
\hline 321 & Wood products & 2.37 & 4.91 \\
\hline 322 & Paper & 2.48 & 1.59 \\
\hline 323 & Printing and related support activities & 1.51 & 10.80 \\
\hline 324 & Petroleum and coal products & 0.65 & 0.66 \\
\hline 325 & Chemicals & 6.47 & 3.81 \\
\hline 326 & Plastics and rubber products & 6.8 & 4.45 \\
\hline 327 & Nonmetallic mineral products & 1.94 & 4.82 \\
\hline 331 & Primary metals & 7.23 & 1.73 \\
\hline 332 & Fabricated metal products & 11.65 & 17.60 \\
\hline 333 & Machinery & 17.58 & 8.17 \\
\hline 334 & Computers and electronic products & 7.34 & 4.56 \\
\hline 335 & Electrical equipment, appliances, and components & 5.29 & 1.86 \\
\hline 336 & Transportation equipment & 8.09 & 3.56 \\
\hline 337 & Furniture and related products & 3.02 & 6.34 \\
\hline \multirow[t]{2}{*}{339} & Miscellaneous products & 10.25 & 9.26 \\
\hline & Total & $100 \%$ & $100 \%$ \\
\hline
\end{tabular}

Notes: ${ }^{1}$ Based on 927 of the 964 manufacturing plants in the sample. The remaining 37 manufacturing plants did not provide an NAICS code.

${ }^{2}$ Source: U.S. Census Bureau, Statistical Abstract of the United States: 2002

ing, and plant performance measures. Manufacturing plants in our sample classify themselves into three types of North American Industry Classification System (NAICS) codes that include discrete, process, and hybrid manufacturing plants. NAICS Code 31 represents plants that manufacture nondurable items, such as food and apparel; NAICS Code 32 represents plants that manufacture raw materials, such as petroleum and chemicals; and NAICS Code 33 represents plants that manufacture machinery and electronics components.

Our usable sample contains 964 plants that provided complete responses to the variables of interest in outsourcing models (Stage 1) and 708 plants for our plant performance models (Stage 2). The net usable response rate of $4.8 \%$ is comparable with that of large plant operations surveys reported in previous empirical studies (Banker et al. 2006; Bardhan, Whitaker, and Mithas 2006). Using the three-digit NAICS codes, Table 1 compares the distribution of the manufacturing plants in our study sample with the distribution of all U.S. manufacturing plants as reported in the "Statistical Abstract of the United States" (U.S. Census Bureau 2002). Our sample has a smaller proportion of nondurable manufacturing plants and a higher proportion of durable manufacturers than the U.S. Census database.

\subsection{Variables Definition}

Gross Margin (MARGIN). We define gross margin as the annual plant revenue less the cost of goods sold
(COGS) as a percentage of plant revenue. Gross margins are influenced by two factors: the price premium that a plant's products command in the marketplace and the efficiency of the plant's outsourcing and internal operational processes. Gross margins reflect a plant's overall profitability and are representative of the financial dimension of a plant's overall operational effectiveness (Kekre and Srinivasan 1990). Previous studies have used similar measures to track plant performance (Zhu and Kraemer 2002).

On-Time Delivery Rate (DEL_RATE). We define on-time delivery rate as the percentage of plant deliveries to the plant's customers that are made within the scheduled delivery window.

Support Process Outsourcing (SUPP_PROC_OUT). Support process outsourcing is a four-item index indicating the extent of plant outsourcing for supporting business processes. The four supporting business processes are warehousing and distribution, IT, transportation, and R\&D. ${ }^{2}$ We measured the degree of outsourcing for each process using a binary variable $(0$ $=$ the process was not outsourced and $1=$ the process was outsourced). Forty-one percent of plants in our sample did not outsource any support processes,

\footnotetext{
${ }^{2}$ Because R\&D processes may be not be considered support functions in some plants, we also reran our empirical analyses after removing R\&D as an item in the SUPP_PROC_OUT index. The empirical results remained unchanged even after exclusion of $R \& D$ as a SUPP_PROC_OUT process.
} 
whereas $40 \%$ of the plants outsourced at least one of the four support activities. Only 1\% of the plants in our sample outsourced all four support processes in 2003.

Production Process Outsourcing (PROD_PROC OUT). Production process outsourcing is a three-item index indicating the extent of plant outsourcing for production processes. The three core production processes include fabrication or processing, assembly, and staging or packaging. We measured the degree of outsourcing for each process using a binary variable $(0$ $=$ the process was not outsourced and $1=$ the process was outsourced). Sixty-three percent of plants in our sample did not outsource any production processes, whereas $35 \%$ of the plants outsourced at least one of the three production processes. Only $2 \%$ of the plants in our sample outsourced all three processes in 2003.

OMS. This is a factor consisting of four types of plant applications that are used to manage plant floor operations and coordinate operational processes, such as inventory control and plant assets. The four OMS applications include warehouse management systems, transportation management systems, asset management systems, and manufacturing execution systems. Each OMS application is measured as a binary variable $(0=$ no usage and $1=$ some or extensive usage).

EMS. EMS is a factor consisting of four types of plant IT systems that plant managers use to coordinate the flow of enterprise-level data across inter- and intraorganizational business processes. The four EMS applications include design systems (e.g., product lifecycle management systems, product data management systems), e-business systems (e.g., customer relationship management systems, electronic data interchange applications), enterprise systems (e.g., ERP), and financial management systems. Enterprise systems include applications that are used to manage enterprise resources, such as ERP systems and material requirements planning systems (e.g., MRP, MRP II). We measure each EMS application as a binary variable based on the extent of plant usage $(0=$ not used and $1=$ some or extensive usage).

Low-Cost Strategy (OUTSTRAT_COST). Lowcost strategy indicates whether a plant's primary reason to outsource its activities is to "reduce costs" (0 $=$ no and $1=$ yes).

Competency-Focused Strategy (OUTSTRAT KNOW). Competency-focused strategy indicates whether a plant's primary reason to outsource its activities is to overcome capacity limitations, gain access to technologies, or gain access to skills $(0=$ no and 1 = yes).
Consistent with previous research, we control for the impact of plant characteristics on business process outsourcing and plant performance. Plant age (AGE) represents the number of years since the plant began operations to the time of the study; this may play a significant role because older plants are less likely to adopt advanced manufacturing practices and often fail to realize their impact on plant performance. Plant size (SIZE) is the number of plant employees. Large plants may have the scale required to justify outsourcing their business processes. The ability to manage outsourcing activities through better supplier integration capabilities may represent an important source of competitive advantage. Accordingly, we control for the impact of supplier integration (SUPPINT) capabilities on plant performance. The SUPPINT variable assesses the extent to which supplier operations, including material deliveries and production planning and scheduling, and plant operations are integrated. We measure this as a binary variable $(0=$ no or some integration and $1=$ extensive integration with suppliers). We control for industry type because industryspecific characteristics are likely to be associated with the extent of plant-level outsourcing that occurs in the industry. Because the plants in our study sample belong to three industry categories, we control for these three types of industry groups in our regression models. Specifically, we use two dummy variables to account for the NAICS 31 and 32 industry groups in our estimation equations.

\subsection{Empirical Models}

We now describe our estimation models to study the antecedents and impact of support and production process outsourcing in greater detail. First, we focus on the antecedents of outsourcing. Because the dependent variables in the outsourcing models, PROD _PROC_OUT and SUPP_PROC_OUT, appear as an ordered choice in our data set, we use an ordered probit model to estimate the first-stage model as specified in Equation (1). ${ }^{3}$ As we described in the previous section, we measure the dependent variable SUPP _PROC_OUT as a summative index of four support activities, and we measure the dependent variable PROD_PROC_OUT as a summative index of three production processes. We express the outsourcing propensities as follows:

$$
\begin{array}{r}
Y_{i}^{*}=\beta_{11} \text { OMS }+\beta_{12} \text { EMS }+\beta_{13} \text { OUTSTRAT_COST } \\
+\beta_{14} \text { OUTSTRAT_KNOW }+\beta_{15} \text { AGE }+\beta_{16} \text { SIZE } \\
+\beta_{17} \text { NAICS_31 }+\beta_{18} \text { NAICS_32 }+e_{1},
\end{array}
$$

where $e_{1} \sim N\left(0, \sigma^{2}\right)$. We do not observe $Y_{i}^{*}$. Instead,

\footnotetext{
${ }^{3}$ We obtain similar results if we use an ordered logit model instead.
} 
we observe the ordinal dependent variables SUPP PROC_OUT or PROD_PROC_OUT; that is, $Y_{j}, j=1,2$, $\ldots, m$, depending on the values of thresholds or cutoff points $\alpha_{j}-1$ and $\alpha_{j}$ as follows:

$$
Y_{i}=j \quad \text { if } \quad \alpha_{j-1}<Y_{i}^{*}<\alpha_{j}
$$

where $\alpha_{j}$ are constants with $\alpha_{0}=-\propto, \alpha_{m}=+\propto$, and $\alpha_{0}<\alpha_{1}<\ldots<\alpha_{m}$.

The probability distribution of $Y_{i}$ is given by

Probability $\left(Y_{i}=j \mid X_{i}\right)$

$$
=\Phi\left[\alpha_{j}-\beta^{\prime} X_{i}\right]-\Phi\left[\alpha_{j-1}-\beta^{\prime} X_{i}\right],
$$

where $\Phi$ denotes the cumulative normal distribution function.

Second, we evaluate the impact of plant production and support outsourcing on plant performance. We examine the impact of SUPP_PROC_OUT and PROD_PROC_OUT and the role of plant IT applications and strategies on two measures of plant performance: gross margins (MARGIN) and on-time delivery rate (DEL_RATE). Our ordinary least squares estimation models for the plant performance models are as follows:

\section{MARGIN}

$$
\begin{aligned}
& =\text { Constant }+\beta_{21} \text { SUPP_PROC_OUT } \\
& +\beta_{22} \text { PROD_PROC_OUT }+\beta_{23} \text { OMS }+\beta_{24} \text { EMS } \\
& +\beta_{25} \text { OUTSTRAT_COST }+\beta_{26} \text { OUTSTRAT_KNOW } \\
& +\beta_{27} \text { SUPPINT }+\beta_{28} \text { AGE }+\beta_{29} \text { SIZE }+\beta_{2,10} \text { NAICS_31 } \\
& +\beta_{2,11} \text { NAICS_32 }+e_{3} \text {, and } \\
& \text { DEL_RATE } \\
& =\text { Constant }+\beta_{31} \text { SUPP_PROC_OUT } \\
& +\beta_{32} \text { PROD_PROC_OUT }+\beta_{33} \text { OMS } \\
& +\beta_{34} \text { EMS }+\beta_{35} \text { OUTSTRAT_COST } \\
& +\beta_{36} \text { OUTSTRAT_KNOW }+\beta_{37} \text { SUPPINT } \\
& +\beta_{38} A G E+\beta_{39} \text { SIZE }+\beta_{3,10} \text { NAICS_32 } \\
& +\beta_{3,11} \text { NAICS_32 }+e_{4} \text {, }
\end{aligned}
$$

where $e_{3}$ and $e_{4}$ are i.i.d. and $N\left(0, \sigma^{2}\right)$. We measure the impact of support outsourcing (SUPP_PROC_OUT) and production outsourcing (PROD_PROC_OUT) on plant performance as specified in Equations (3) and (4). Our use of ordered probit to estimate Equation (2) and ordinary least squares to estimate Equations (3) and (4) provides consistent and efficient estimates because this system of equations represents a recursive model (Greene 2000).

\section{Results}

Table 2 provides descriptive statistics for our model variables, including the mean, standard deviation, and zero-order correlation between model variables. The zero-order correlations are less than 0.5 in all cases, which suggests that multicollinearity is not an issue in our regression estimation models. The correlation between OUTSTRAT_COST and OUTSTRAT_KNOW is -0.444 , which suggests that plants that focus on a low-cost strategy are less likely to focus on differentiation strategies through access to external skills, technologies, and resources.

Our use of two classes of IT applications is based on theoretical considerations. However, consistent with practice in previous research (Banker et al. 2006), we assessed the validity of the classification of IT applications in two categories by conducting exploratory factor analyses (EFA) on the plant IT variables, using principal component analysis with varimax rotation. ${ }^{4}$ Table 3 illustrates the EFA results for the plant IT variables and indicates the presence of two IT factors that account for $48 \%$ of the variance. The factor structures represent the usage of two classes of plant-level IT applications-OMS and EMS-that are consistent with the factors that we proposed in our research model. The cross-factor loadings are small, and each factor had one eigenvalue greater than 1 , which suggests that our factors are unidimensional. Cronbach's alphas for the two factors are 0.69 and 0.70 , indicating reasonably good internal consistency of the factors. We now describe the results of our empirical estimation of the antecedents and performance outcomes of production and support process outsourcing.

\subsection{Antecedents of Outsourcing}

The ordered probit estimation results for the SUPP PROC_OUT model in Equation 2 appear in Column 1 of Table 4. The probit results indicate that although the association between the implementation of plant OMS and SUPP_PROC_OUT is positive, it is not statistically significant $\left(\beta_{11}=0.006, p=0.873\right)$. The results also indicate a positive, statistically significant association between implementation of plant-level EMS and the extent of support process outsourcing $\left(\beta_{12}=0.081, p\right.$ $=0.037)$. Thus, the results do not support Hypothesis $1 \mathrm{a}$, but they support Hypothesis $1 \mathrm{~b}$.

The ordered probit estimation results for the PROD_ PROC_OUT model, as we demonstrate in Column 2 of Table 4 , are similar to the SUPP_PROC_OUT model.

\footnotetext{
${ }^{4}$ We used a split-sample approach, in which a calibration sample (half of our total sample) was used to conduct the EFA. We then reran the EFA using the holdout sample and observed that the factor structures using the holdout sample were consistent with those generated from the calibration sample
} 
Table 2 Descriptive Statistics and Correlations

\begin{tabular}{|c|c|c|c|c|c|c|c|c|c|c|c|c|}
\hline & $\mathrm{N}$ & $\begin{array}{c}\text { Mean } \\
(\mathrm{SD})\end{array}$ & 1 & 2 & 3 & 4 & 5 & 6 & 7 & 8 & 9 & 10 \\
\hline 1. SUPP_PROC_OUT & 964 & $\begin{array}{c}0.83 \\
(0.85)\end{array}$ & & & & & & & & & & \\
\hline 2. PROD_PROC_OUT & 964 & $\begin{array}{l}0.47 \\
(0.70)\end{array}$ & 0.070 & & & & & & & & & \\
\hline 3. Gross margin & 715 & $\begin{array}{l}0.34 \\
(0.20)\end{array}$ & 0.033 & 0.098 & & & & & & & & \\
\hline 4. On-time delivery rate & 964 & $\begin{array}{c}0.91 \\
(0.12)\end{array}$ & 0.014 & -0.108 & -0.075 & & & & & & & \\
\hline 5. OMS & 964 & $\begin{array}{c}0.00 \\
(1.00)\end{array}$ & -0.006 & -0.050 & -0.025 & 0.091 & & & & & & \\
\hline 6. EMS & 964 & $\begin{array}{c}0.00 \\
(1.00)\end{array}$ & 0.106 & 0.164 & -0.061 & 0.107 & -0.215 & & & & & \\
\hline 7. OUTSTRAT_COST & 964 & $\begin{array}{l}0.36 \\
(0.48)\end{array}$ & 0.263 & 0.166 & -0.040 & 0.007 & 0.062 & 0.096 & & & & \\
\hline 8. OUTSTRAT_KNOW & 964 & $\begin{array}{c}0.26 \\
(0.44)\end{array}$ & 0.094 & 0.207 & 0.058 & -0.023 & -0.096 & 0.065 & -0.444 & & & \\
\hline 9. SUPPINT & 935 & $\begin{array}{c}0.19 \\
(0.39)\end{array}$ & 0.017 & -0.054 & -0.023 & 0.074 & 0.118 & 0.061 & 0.047 & -0.055 & & \\
\hline 10. AGE & 964 & $\begin{array}{l}3.59 \\
(0.76)\end{array}$ & -0.028 & -0.021 & 0.012 & -0.127 & -0.057 & 0.055 & 0.033 & -0.016 & -0.066 & \\
\hline 11. SIZE & 964 & $\begin{array}{l}1.77 \\
(1.02)\end{array}$ & 0.053 & 0.029 & -0.109 & 0.155 & 0.140 & 0.303 & 0.118 & -0.076 & 0.085 & 0.125 \\
\hline
\end{tabular}

All correlations greater than or equal to 0.066 are statistically significant at $p<0.05$.

The results indicate that the association between OMS usage and likelihood of production outsourcing is not significant. However, they also suggest a strong association between implementation of EMS applications and the extent of production outsourcing $\left(\beta_{22}=0.155\right.$, $p=0.001)$. Thus, the results provide only partial support for Hypothesis 2; specifically, Hypothesis 2a is not supported, but there is strong support for Hypothesis $2 \mathrm{~b}$. $^{5}$

Consistent with Hypothesis 3, the estimation results indicate that both types of plant outsourcing strategies

${ }^{5}$ We also tested for the equality of estimated coefficients between OMS and EMS for the SUPP_PROC_OUT and PROD_PROC_OUT models. The results indicate that EMS has a greater impact than OMS for both models, although the difference is statistically significant at $p<0.01$ only for the PROD_PROC_OUT model (Wald $\chi^{2}$ $=10.89$ ). have a positive association with the extent of outsourcing of plant processes. The results suggest that plants that are focused on low cost as a primary motivation for outsourcing are more likely to outsource their support business processes $\left(\beta_{13}=0.863, p\right.$ $<0.000)$. The results also indicate that plants that are focused primarily on gaining "competencies through external means," such as access to new technologies, skills, or resources, are also likely to outsource their supporting processes $\left(\beta_{14}=0.670, p<0.000\right)$. In a similar vein, the PROD_PROC_OUT results are consistent with our SUPP_PROC_OUT results and indicate a strong association between cost- and competency-focused plant strategies with the likelihood of production outsourcing. Thus, the results support Hypotheses $3 a$ and $3 b$.

We also test the equality of estimated coefficients

Table 3 Exploratory Factor Analysis Results for IT Factors

\begin{tabular}{llrr}
\hline Factor Name & \multicolumn{1}{c}{ Indicator } & Factor 1 & Factor 2 \\
\hline Plant operations management systems (OMS) $(\alpha=0.68)$ & Warehouse management systems & 0.761 & 0.060 \\
& Transportation management systems & 0.689 & 0.154 \\
& Asset management & 0.654 & 0.212 \\
Enterprise management systems (EMS) $(\alpha=0.70)$ & Manufacturing execution systems & 0.589 & 0.091 \\
& Design systems (PLM, PDM, CAD, CAE) & 0.109 & 0.047 \\
& E-business systems (CRM, EDI) & 0.147 & 0.733 \\
& Enterprise systems (ERP, MRP, MRP II) & 0.322 & 0.581
\end{tabular}

All factor loadings shown in bold are statistically significant at $p<0.01$ 


\begin{tabular}{lll} 
Table 4 & $\begin{array}{l}\text { Ordered Probit Estimation Results for the Support and } \\
\text { Production Outsourcing Models }\end{array}$ & \multicolumn{1}{c}{$(1)$} \\
& \multicolumn{1}{c}{$(2)$} \\
& SUPP_PROC_OUT & PROD_PROC_OUT \\
\hline OMS & $\beta_{11} 0.006$ & $\beta_{21}-0.039$ \\
& $(0.873)$ & $(0.351)$ \\
EMS & $\beta_{12} 0.081^{\star \star}$ & $\beta_{22} 0.155^{\star \star \star}$ \\
& $(0.037)$ & $(0.001)$ \\
OUTSTRAT_COST & $\beta_{13} 0.863^{\star \star *}$ & $\beta_{23} 0.916^{\star \star \star}$ \\
& $(0.000)$ & $(0.000)$ \\
OUTSTRAT_KNOW & $\beta_{14} 0.670^{\star \star \star}$ & $\beta_{24} 0.993^{\star \star \star}$ \\
& $(0.000)$ & $(0.000)$ \\
AGE & $\beta_{15}-0.058$ & $\beta_{25}-0.095^{\star}$ \\
& $(0.224)$ & $(0.068)$ \\
SIZE & $\beta_{16} 0.040$ & $\beta_{26}-0.015$ \\
& $(0.283)$ & $(0.729)$ \\
NAICS_31 & $\beta_{17} 0.169$ & $\beta_{27}-0.339^{*}$ \\
& $(0.240)$ & $(0.053)$ \\
NAICS_32 & $\beta_{18} 0.061$ & $\beta_{28}-0.258^{\star \star}$ \\
& $(0.495)$ & $(0.012)$ \\
N & 964 & 964 \\
Likelihood ratio $\chi^{2}$ & 124.41 & 152.06 \\
$p$-value & 0.000 & 0.000 \\
Max-rescaled R-square & $13.43 \%$ & $17.52 \%$ \\
\hline
\end{tabular}

One-tailed $p$-values are shown in parentheses. ${ }^{* \star} p<.05 ;{ }^{* \star \star} p<0.01$.

between OUTSTRAT_COST and OUTSTRAT_ KNOW. For the SUPP_PROC_OUT model, the coefficient on OUTSTRAT_COST $\left(\beta_{13}=0.863\right)$ is greater than that on OUTSTRAT_KNOW $\left(\beta_{14}=0.670\right)$. The Wald chi-square statistic for this test is 4.50 and is significant at the 0.05 level, suggesting that low-cost outsourcing strategy has a greater impact on SUPP_ PROC_OUT than competency-focused strategies. For the PROD_PROC_OUT model, there is no significant difference between the two coefficients, suggesting that plants that adopt either type of outsourcing strategy are equally likely to outsource their production processes.

Among the control variables, we determine no statistically significant differences in the likelihood of outsourcing plant support processes across different industry groups in our sample. However, the results indicate that there are differences in the likelihood of outsourcing plant production processes across industries. Plants in the process and basic materials industries (NAICS 31 and NAICS 32) are less likely to outsource their core production processes than hightech and industrial equipment manufacturers (NAICS 33). This is consistent with our expectations; process manufacturing processes are inherently more difficult to outsource because such processes cannot be easily modularized or decoupled from other plant processes (Mithas and Whitaker 2007).

\subsection{Plant Performance}

Table 5 provides our estimation results for plant per- formance. Column 1 provides the regression estimates for gross margin (MARGIN), and Column 2 provides the estimates for on-time delivery rate (DEL_RATE).

Hypothesis 4a posits that plants that outsource their supporting business processes are more likely to realize higher gross margins. This hypothesis is supported because SUPP_PROC_OUT has a positive association with plant gross margins $\left(\beta_{21}=0.016, p=0.047\right)$. The results also indicate that the extent of PROD_PROC_OUT has a positive, significant impact on MARGIN $\left(\beta_{22}=0.038, p\right.$ $=0.001)$, in support of Hypothesis $4 \mathrm{~b}$. Furthermore, the magnitude of the overall impact of PROD_PROC_OUT on MARGIN is more than twice the impact of SUPP PROC_OUT.

Column 2 of Table 5 provides our regression estimates for DEL_RATE. We do not find support for Hypothesis 5a, because SUPP_PROC_OUT does not have a significant impact on DEL_RATE $\left(\beta_{31}=0.003\right.$, $p=0.266$ ). Furthermore, contrary to Hypothesis $5 \mathrm{~b}$, the results indicate that PROD_PROC_OUT is negatively associated with DEL_RATE $\left(\beta_{32}=-0.017, p\right.$ $=0.001)$. Taken together, the results for Hypotheses 4 and 5 indicate that there may be trade-offs between improvements in the two dimensions of plant perfor-

Table $5 \quad$ Plant Performance Models

\begin{tabular}{|c|c|c|}
\hline & $\begin{array}{l}\text { Gross Margin } \\
\text { (1) }\end{array}$ & $\begin{array}{l}\text { On-Time Delivery Rate } \\
\text { (2) }\end{array}$ \\
\hline SUPP_PROC_OUT & $\begin{array}{l}\beta_{11} 0.016^{\star \star} \\
(0.047)\end{array}$ & $\begin{array}{l}\beta_{21} 0.003 \\
(0.266)\end{array}$ \\
\hline PROD_PROC_OUT & $\begin{array}{l}\beta_{12} 0.038^{\star \star \star} \\
(0.001)\end{array}$ & $\begin{array}{l}\beta_{22}-0.017^{\star \star \star} \\
(0.001)\end{array}$ \\
\hline OMS & $\begin{array}{l}\beta_{13} 0.001 \\
(0.476)\end{array}$ & $\begin{array}{l}\beta_{23} 0.010^{\star \star \star} \\
(0.005)\end{array}$ \\
\hline EMS & $\begin{array}{l}\beta_{14}-0.025^{\star \star \star} \\
(0.002)\end{array}$ & $\begin{array}{l}\beta_{24} 0.016^{\star \star \star} \\
(0.000)\end{array}$ \\
\hline OUTSTRAT_COST & $\begin{array}{l}\beta_{15}-0.023 \\
(0.116)\end{array}$ & $\begin{array}{l}\beta_{25} 0.004 \\
(0.316)\end{array}$ \\
\hline OUTSTRAT_KNOW & $\begin{array}{l}\beta_{16} 0.005 \\
(0.411)\end{array}$ & $\begin{array}{l}\beta_{26}-0.005 \\
(0.288)\end{array}$ \\
\hline SUPPINT & $\begin{array}{l}\beta_{17} 0.002 \\
(0.453)\end{array}$ & $\begin{array}{l}\beta_{27}-0.019^{* *} \\
(0.021)\end{array}$ \\
\hline AGE & $\begin{array}{l}\beta_{18} 0.012 \\
(0.120)\end{array}$ & $\begin{array}{l}\beta_{28}-0.009^{\star *} \\
(0.031)\end{array}$ \\
\hline SIZE & $\begin{array}{l}\beta_{19}-0.010 \\
(0.105)\end{array}$ & $\begin{array}{l}\beta_{29} 0.011^{\star \star \star} \\
(0.001)\end{array}$ \\
\hline NAICS_31 & $\begin{array}{l}\beta_{110}-0.014 \\
(0.323)\end{array}$ & $\begin{array}{l}\beta_{210} 0.028^{\star *} \\
(0.025)\end{array}$ \\
\hline NAICS_32 & $\begin{array}{l}\beta_{111}-0.002 \\
(0.452)\end{array}$ & $\begin{array}{l}\beta_{211} 0.013^{\star} \\
(0.074)\end{array}$ \\
\hline Intercept & $\begin{array}{l}\beta_{112} 0.299^{\star \star \star} \\
(0.000)\end{array}$ & $\begin{array}{l}\beta_{212} 0.934^{\star \star *} \\
(0.000)\end{array}$ \\
\hline $\mathrm{N}$ & 708 & 935 \\
\hline F-statistic ( $p$-value) & $\begin{array}{l}2.39^{\star \star \star} \\
(0.007)\end{array}$ & $\begin{array}{l}5.87^{\star \star *} \\
(0.000)\end{array}$ \\
\hline Adjusted $\mathrm{R}^{2}$ & $2.12 \%$ & $5.42 \%$ \\
\hline
\end{tabular}


mance, namely, gross margins and the incidence of on-time delivery.

The results suggest that plants that implement EMS have lower gross margins $\left(\beta_{24}=-0.025, p=0.002\right)$, whereas the implementation of plant OMS applications does not have a significant association with gross margins $\left(\beta_{23}=0.001, p=0.427\right)$. In addition to considering these direct (marginal) effects of IT applications on plant performance, we recognize the indirect impact of IT on MARGIN through its impact on the outsourcing of production and support processes. The results indicate that the impact of IT on plant gross margins is mediated through its ability to facilitate the outsourcing of plant production and support processes. The mediated path (i.e., EMS $\rightarrow$ PROD_PROC_OUT $\rightarrow$ MARGIN) is positive and statistically significant $(z$-statistic $=2.291) .{ }^{6}$ Furthermore, although the mediated path through SUPP_PROC_ OUT (i.e., EMS $\rightarrow$ SUPP_PROC_OUT $\rightarrow$ MARGIN) is positive, it is not significant at $p<0.05$. Thus, plant IT applications enable implementation of PROD_PROC_ OUT, which, in turn, is associated with higher gross margins.

The results indicate that both classes of plant IT applications have a direct, positive association with DEL_RATE. Specifically, OMS applications that are used to manage factory-level operations have a positive impact on plant on-time delivery rates $\left(\beta_{33}=\right.$ $0.010, p=0.005)$, and the usage of EMS applications to coordinate information flow across inter- and intraorganizational processes is associated with a greater adherence to delivery schedules $\left(\beta_{34}=0.016, p=0.000\right)$. In addition, IT applications have an indirect impact on delivery schedules through plant outsourcing. The overall effect of plant IT infrastructure on DEL_RATE can be viewed as a sum of two effects: (a) a direct impact on DEL_RATE and (b) a mediated effect through SUPP_PROC_OUT and PROD_PROC_OUT. Our estimation of the overall effect of OMS on DEL RATE shows a significant, positive association (coefficient $=0.01, z$-statistic $=2.66$ ), and EMS is also positively associated with greater DEL_RATE (coefficient $=0.015, z$-statistic $=3.85$ ).

Plant outsourcing strategies do not have a direct impact on gross margins. However, they have a mediated effect on MARGIN through their impact on outsourcing of production and support processes. For example, the mediation effects of OUTSTRAT_COST on MARGIN through PROD_PROC_OUT (coefficient $=0.016, z$-statistic $=3.04)$ nd SUPP_PROC_OUT $($ coefficient $=0.009, z$-statistic $=1.65$ ) are both positive

\footnotetext{
${ }^{6}$ We used the OLS estimation results to compute the value of the mediated path coefficients. The probit estimation results are similar to OLS results in terms of the sign and significance of estimated regression coefficients.
}

and statistically significant. We also demonstrate that OUTSTRAT_KNOW has a positive association with gross margin through PROD_PROC_OUT (coefficient $=0.017$, z-statistic $=3.03$ ). However, we do not detect support for a significant association of OUTSTRAT_ KNOW with gross margin through SUPP_PROC_ OUT (coefficient $=0.007, z$-statistic $=1.62$ ).

The results indicate no statistically significant, direct relationship between plant outsourcing strategies and DEL_RATE. Conversely, the test of indirect effects shows that both OUTSTRAT_COST (coefficient $=-0.007, z$-statistic $=2.95)$ and OUTSTRAT_KNOW (coefficient $=-0.007, z$-statistic $=2.94$ ) have a negative impact on plant on-time delivery rate through PROD_PROC_OUT. The mediated paths through SUPP_PROC_OUT for OUTSTRAT_COST (coefficient $=0.002, z$-statistic $=0.63$ ) and OUTSTRAT_KNOW (coefficient $=0.001, z$-statistic $=0.63$ ) are positive but not statistically significant.

Among the control variables, we observe that older plants are more likely to be associated with lower on-time delivery rates, whereas larger plants are more likely to be associated with higher on-time delivery rates, ceteris paribus. This may be because larger plants are more likely to have the resources and capabilities necessary to improve plant processes and on-time delivery, whereas older plants are less likely to have such resources and capabilities. The results also suggest that plants in durable (NAICS 31) and basic materials (NAICS 32) industries exhibit a positive association with higher on-time delivery rates. These results suggest that plant and industry characteristics play important roles in terms of their impact on plant performance.

\section{Discussion}

\subsection{Findings}

Our goal in this study was to understand how outsourcing strategies (low cost versus competency focused) and specific IT applications (EMS versus OMS) affect production and support outsourcing and the subsequent impact on profitability and on-time delivery. Consistent with our expectations, we find that the role of EMS is important in facilitating the outsourcing of production and support business processes. This may be because the implementation of EMS applications enables plants to collaborate within and across organizational boundaries by providing the technological capabilities to support interorganizational information exchange, joint decision making, and greater visibility of suppliers' operations to plant personnel. We do not detect any effect of OMS on the outsourcing of business processes. A possible explanation for this finding is that OMS are not as effective 
as EMS applications in facilitating the outsourcing and coordination of activities with external business partners. Therefore, plants with a greater need for the outsourcing of business processes should consider the differential impact of investments in IT systems.

Although both low-cost and competency-focused strategies influence the outsourcing of production and support processes, plants with low-cost outsourcing strategies are far more likely to outsource support processes than plants with competency-focused outsourcing strategies. These results are consistent with conventional thinking because low-cost strategies are associated with a greater outsourcing of plant support and production processes. However, they also challenge conventional wisdom because outsourcing is not associated only with low-cost strategies. Indeed, our results imply that plants that focus on competencybased strategies that include differentiation through access to external resources, skills, and technologies are also likely to outsource their production and supporting business processes. These results suggest that the notion of outsourcing is not inconsistent with the strategy to leverage the capabilities of a network of partners and suppliers to complement plants' existing core capabilities.

In terms of implications for plant performance, our results indicate that although the outsourcing of both support and production processes is associated with higher gross margins, production outsourcing has a much greater impact on gross margins. Notably, plant outsourcing does not have a favorable impact on ontime delivery, an important measure of plant operational quality and a determinant of customer satisfaction. Because customer satisfaction has significant implications for market value and stock returns (Fornell et al. 2006), managers should weigh the profitability and customer satisfaction impact of their outsourcing decisions, particularly when they suspect that increased short-term profitability may compromise longer-term customer value. One way to avoid some of these trade-offs may be to invest in customer relationship management systems, which have been shown to be associated with improved customer knowledge and customer satisfaction (Mithas, Krishnan, and Fornell 2005a).

Although we do not demonstrate support for the direct effect of IT systems on plant profitability, EMS affect profitability through their enabling role in production outsourcing. This validates suggestions in previous research about the importance of correctly modeling the impact of IT on performance, in particular to assess profitability (Dedrick, Gurbaxani, and Kraemer 2003). As in other studies that either failed to find an effect of IT on profitability or determined a negative overall impact (Hitt and Brynjolfsson 1996;
Rai, Patnayakuni, and Patnayakuni 1997), our results also suggest a negative overall impact of EMS on profitability. However, it is likely that EMS also significantly and positively affect profitability through other mechanisms and organizational capabilities (Mithas, Bardhan, and Goh 2006b), and by considering these capabilities, further research may uncover a positive impact of IT on profitability.

Although the findings of this study are not strictly comparable with those of Bardhan, Whitaker, and Mithas (2006) because of the differences in underlying survey data and some of the key previously noted constructs, we can offer some broad conclusions that are informative. First, unlike Bardhan, Whitaker, and Mithas (2006), who examine the impact of aggregate IT spending on production outsourcing and firm performance, this study focuses on the effect of EMS and OMS applications on both production and support outsourcing and traces this impact on profitability and on-time delivery. Although Bardhan, Whitaker, and Mithas establish that a plant's aggregate IT spending is positively associated with production outsourcing, the current study indicates that not all IT investments are associated with greater outsourcing. Instead, EMS applications are associated with the incidence of outsourcing, whereas OMS applications are not associated with outsourcing.

Second, in contrast to Bardhan, Whitaker, and Mithas (2006), this study examines plant outsourcing strategies directly and examines their relationship to plant outsourcing activities. Although it may be suspected that a low-cost plant strategy emphasizes a low-cost outsourcing strategy, this is not always the case (Gottfredson, Puryear, and Phillips 2005). Although Bardhan, Whitaker, and Mithas (2006) do not detect any association between a low-cost plant strategy and production process outsourcing, this study demonstrates that at a more disaggregated level, lowcost outsourcing strategies are significantly associated with production process outsourcing. This finding highlights the importance of distinguishing between broad plant-level strategies and more specific outsourcing strategies because they yield different insights.

Finally, this study uses gross margin, a measure that captures both revenue effect and cost effect. In contrast, Bardhan, Whitaker, and Mithas (2006) use a more focused and narrowly defined COGS measure to assess financial impact of production outsourcing. Taken together, the results of these two studies indicate that production outsourcing helps improve gross margin perhaps by reducing cost (as measured by COGS), rather than through a price increase, because Bardhan, Whitaker, and Mithas (2006) also determine that outsourcing is associated with lower prices 
charged to customers. The current study suggests that production outsourcing has a negative association with plant on-time delivery rate, which is consistent with the findings of Bardhan, Whitaker, and Mithas (2006), who report that production outsourcing has a negative impact on lead time. Although many anecdotal and case study accounts suggest that outsourcing can provide cycle time benefits, together these plant-level studies that control for other plant characteristics indicate that achieving cycle time benefits may not be easy.

\subsection{Implications}

This study provides two important implications for further research. First, although we established the role of IT application infrastructure in terms of its association with plant outsourcing and profitability, there is a need to understand the extent to which the effect of IT on profitability is mediated through revenue growth and cost reduction. Although previous research has suggested that IT investments may allow firms to achieve both revenue growth and cost reduction objectives simultaneously (Anderson, Fornell, and Rust 1997), we are not aware of any studies that have empirically tested this claim. Because previous studies that have used pre-1995 data have failed to detect the effect of IT on profitability (Hitt and Brynjolfsson 1996; Rai, Patnayakuni, and Patnayakuni 1997), mediated models with more recent data may afford better opportunities for assessing the impact of IT on profitability, as some researchers suggest (Andal-Ancion, Cartwright, and Yip 2003; Dedrick, Gurbaxani, and Kraemer 2003).

A second implication for future research is that the IT governance strategies may also affect plant performance. However, few studies have examined the role of IT strategies on firm performance and whether revenue growth or cost reduction-focused IT strategies might moderate the effect of IT investments on firm performance.

The current study has several implications for practice. First, this study suggests that greater usage of EMS is associated with a higher likelihood of outsourcing plant support processes. This implies that investments in plant IT application infrastructure are important for managers to coordinate their operations with outsourcing providers effectively. The results are supported by anecdotal evidence from industry studies. For example, the toy manufacturer Hasbro, Inc., invests heavily in IT to coordinate its value chain and collaborate effectively with its network of contract manufacturers (Chung, Yam, and Chan 2004). Hasbro's Far East operations use an information portal to coordinate product design, assembly, logistics, and manufacturing functions that are outsourced to a net- work of suppliers and contract manufacturers. The information portal provides a single point of contact for Hasbro, its retail customers, and a network of Tier 1 and 2 suppliers.

Second, this study suggests that plants with costfocused strategies do not necessarily favor the outsourcing of supporting business processes. Rather, the results imply that plants with competency-focused outsourcing strategies are also likely to outsource their supporting business functions because outsourcing allows plants to access critical external competencies and technological resources that may not be available in-house or cannot be performed internally in a costeffective manner.

Third, the results imply that although support outsourcing has a positive, significant impact on plant gross margins, production outsourcing has a far greater impact on gross margins. In other words, decisions to outsource core production processes have a greater impact on plant financial performance than the outsourcing of support processes.

Fourth, the results imply that it is important to measure plant performance along multiple dimensions. Although a focus on the financial dimension alone may indicate that outsourcing has a positive association with gross margins, our findings imply that outsourcing does not have a favorable impact on on-time delivery rate. Managers must consider these trade-offs in profitability and timeliness dimensions as they make decisions about their IT investment and outsourcing strategies. Finally, our results imply that managers should not focus only on the direct impact of IT on plant performance when they make IT investments decisions. Rather, it seems that the impact of IT on plant performance is partially mediated through its role as an enabler of support and production outsourcing.

It could be argued that studies that provide recommendations for policy changes based on archival data are subject to the Lucas critique if economic agents are aware of these policy changes and are both motivated and able to change their behavior as a consequence of such policy change. However, the Lucas critique does not seem to apply to this study, because the parties affected by the managerial implications and actions could not have modified their behavior a priori, thus rendering our recommendations invalid. Furthermore, there appears to be little support for the empirical validity of the Lucas critique in settings similar to ours (van Heerde, Deimpe, and Putsis 2005).

\subsection{Limitations and Suggestions for Further Research}

We acknowledge several limitations of this study. First, because of the cross-sectional nature of our data, the findings demonstrate only associational patterns. 
Further examination of the overall impact of outsourcing on plant operational performance using panel data across a longer time frame is desirable to study the lagged relationship among IT infrastructure, outsourcing, and plant performance. Longitudinal data will also make it possible to deal with some of the endogeneity and parameter heterogeneity issues that are difficult to address in a cross-sectional study (Gonul and Srinivasan 1993; Murthi, Srinivasan, and Kalyanaram 1996). Although we do not have access to panel data, the associational patterns in this study provide a starting point for future longitudinal studies. In addition, from a methodological perspective, it would be useful to employ a potential outcomesbased propensity score approach (e.g., Dehejia and Wahba 2002; Mithas, Almirall, and Krishnan 2006a; Rubin and Waterman 2006) to gain a more complete understanding of the extent to which the effect of outsourcing on performance sustains a causal interpretation.

Second, the MPI data set does not provide information on the extent of outsourcing for each business process (e.g., percentages of transactions in the "warehousing and distribution" and "logistics" processes), which may provide a richer understanding of the antecedents and performance outcomes of outsourcing. A more accurate picture of the extent to which transactions are outsourced can provide a deeper understanding of the impact of support and production outsourcing. Third, our data set does not provide information on the managerial skills that may be necessary to realize the benefits of outsourcing decisions. A closer investigation of the business and IT skills of plant professionals and how these competencies and related human resource policies affect outsourcing decisions and performance in manufacturing plants may provide a fruitful avenue for further research (Dischinger et al. 2006; Ramasubbu, Mithas, and Krishnan 2008; Tafti, Mithas, and Krishnan 2007).

Finally, our findings can be further supplemented through extensive field studies within organizations to develop a rich, process-level database to study the antecedents and outcomes of outsourcing across a wider range of value chain processes. Such studies could provide a better contextual understanding of the impact of IT and plant and industry strategies on the outsourcing of critical business processes. Likewise, further research should also investigate the antecedents of onshore and offshore business process outsourcing and the role of IT infrastructure in such decisions and implications for firm performance.

To conclude, this study developed and empirically tested a model for the effect of IT application infrastructure and outsourcing strategies on the outsourcing of plant support and production processes, as well as their impact on plant performance. Using data from a cross-section of U.S. manufacturing plants, we determined that the implementation of EMS is positively associated with the incidence of outsourcing of plant processes. In turn, the implementation of support and production process outsourcing is associated with higher plant gross margins. Plant outsourcing strategies also play an important role in determining the extent of outsourcing. Specifically, we found a positive association between the adoption of low-cost and competency-focused outsourcing strategies and the outsourcing of plant production and supporting business processes. These results highlight the role of plant-level IT infrastructure and outsourcing strategies in the outsourcing of plant support and production processes for improved performance and competitive advantage.

\section{Acknowledgments}

We gratefully acknowledge comments on earlier versions of the manuscript from Sarv Devaraj, Jonathan Whitaker, participants at the First International Symposium of Information Systems at Indian School of Business, Hyderabad, and seminar participants at the University of Texas at Dallas. Financial support was provided, in part, by the University of Texas at Dallas School of Management and the R.H. Smith School of Business at the University of Maryland. We thank John Brandt and the Manufacturing Performance Institute for providing us with data for this study. The views and findings of this paper are entirely the responsibility of the authors and do not represent the views of MPI or IndustryWeek.

\section{References}

Andal-Ancion, A., P. A. Cartwright, G. S. Yip. 2003. The digital transformation of traditional businesses. MIT Sloan Management Review 44(4) 34-41.

Anderson, E. W., C. Fornell, R. T. Rust. 1997. Customer satisfaction, productivity, and profitability: Differences between goods and services Marketing Science 16(2) 129-145.

Apte, U. M., R. O. Mason. 1995. Global disaggregation of information-intensive services. Management Science 41(7) 1250-1262.

Aral, S., E. Brynjolfsson, D. J. Wu. 2006. Which came first, IT or productivity? The virtuous cycle of investment \& use in enterprise systems, in Proceedings of the 27th International Conference on Information Systems, AIS, Milwaukee, WI.

Banker, R. D., I. R. Bardhan, S. Lin, H. Chang. 2006. Plant information systems manufacturing capabilities and plant performance. MIS Quarterly 30(2) 315-337.

Bardhan, I. R. 2007. Toward a theory to study the use of collaborative product commerce for product development. Information Technology and Management 8(2) 167-184.

Bardhan, I. R., J. Whitaker, S. Mithas. 2006. Information technology production process outsourcing and manufacturing plant performance. Journal of Management Information Systems 23(2) 1340.

Barua, A., T. Mukhopadhyay. 2000. Information technology and business performance: past, present, and future in Framing the domains of information technology management: projecting the future through the past R. W. Zmud (ed.), Pinnaflex Press, Cincinnati, Ohio, 65-84. 
Bettis, R. A., S. P. Bradley, G. Hamel. 1992. Outsourcing and industrial decline. Academy of Management Executive 6(1) 7-22.

Boyer, K. K., M. Swink, E. D. Rosenzweig. 2005. Operations strategy research in the POMS journal. Production and Operations Management 14(4) 442-449.

Brynjolfsson, E., L. Hitt. 1996. Paradox lost? Firm-level evidence on the returns to information systems spending. Management Science, 42(4) 541-558.

Buhman, C., S. Kekre, J. Singhal. 2005. Interdisciplinary and interorganizational research: Establishing the science of enterprise networks. Production and Operations Management 14(4) 493-513.

Choudhury, V., K. S. Hartzel, B. R. Konsynski. 1998. Uses and consequences of electronic markets: An empirical investigation in the aircraft parts industry MIS Q 22(4) 471-507.

Chung, W. C. C., A. Y. K. Yam, M. F. S. Chan. 2004. Networked enterprise: A new business model for global sourcing. International Journal of Production Economics 87 267-280.

Clemons, E. K., S. P. Reddi, M. C. Row. 1993. The impact of information technology on the organization of economic activity: The "move to the middle" hypothesis. Journal of Management Information Systems 10(2) 9-35.

Cotteleer, M. J. 2006. An empirical study of operational performance parity following enterprise system deployment. Production and Operations Management 15(1) 74-87.

Cotteleer, M. J., E. Bendoly. 2006. Order lead-time improvement following enterprise-IT implementation: An empirical study. MIS Q 30(3) 643-660.

Dedrick, J., V. Gurbaxani, K. L. Kraemer. 2003. Information technology and economic performance: A critical review of empirical evidence. ACM Computing Surveys 35(1) 1-28.

Dehejia, R. H., S. Wahba. 2002. Propensity score-matching methods for nonexperimental causal studies. Review of Economics and Statistics 84(1) 151-161.

Deloitte Consulting. 2005. Calling a change in the outsourcing market: The realities for the world's largest organizations www. deloitte.com/dH/cda/doc/content/us_outsourcing_callingachange.pdf.

Dess, G. G., A. A. Rasheed, K. J. McLaughlin, R. L. Priem. 1995. The new corporate architecture. Academy of Management Executive 9(3) $7-20$.

Dibbern, J., T. Goles, R. Hirschheim, B. Jayatilaka. 2004. Information systems outsourcing: A survey and analysis of the literature. The Database for Advances in Information Systems 35(4) 6-102.

Dischinger, J., D. J. Closs, E. McCulloch, C. Speier, W. Grenoble, D. Marshall. 2006. The emerging supply chain management profession. Supply Chain Management Review 10(1) 62-78.

Engardio, P., B. Einhorn, M. Kripalani, A. Reinhardt, B. Nussbaum, P. Burrows. 2005. Outsourcing innovation in Business Week (Issue 3925, March 21, 2005), 84-91.

Fornell, C., S. Mithas, F. Morgeson, M. S. Krishnan. 2006. Customer satisfaction and stock prices: High returns, low risk. Journal of Marketing 70(1) 3-14.

Gonul, F., K. Srinivasan. 1993. Modeling multiple sources of heterogeneity in multinomial logit models: Methodological and managerial implications. Marketing Science 12 213-229.

Gosain, S., A. Malhotra, O. A. El Sawy. 2005. Coordination for flexibility in e-business supply chains. Journal of Management Information Systems 21(3) 7-45.

Gottfredson, M., R. Puryear, S. Phillips. 2005. Strategic sourcing: From periphery to the core. Harvard Business Review 83(2) 132139.

Grant, R., C. Baden-Fuller. 2004. A knowledge accessing theory of strategic alliances. Journal of Management Studies 41(1) 61-84.
Grant, R. M. 1996. Towards a knowledge-based theory of the firm. Strategic Management Journa, 17(Winter Special Issue) 109-122.

Greene, W. H. 2000. Econometric Analysis (4th ed.). Prentice Hall, Upper Saddle River, New Jersey.

Hendricks, K. B., V. R. Singhal. 2005. An empirical analysis of the effect of supply chain disruptions on long-run stock price performance and equity risk of the firm. Production and Operations Management 14(1) 35-52.

Hitt, L. M., E. Brynjolfsson. 1996. Productivity, business profitability, and consumer surplus: Three different measures of information technology value. MIS Q 20(2) 121-142.

Hitt, L. M., D. J. Wu, X. Zhou. 2002. Investments in enterprise resource planning: Business impact and productivity measures Journal of Management Information Systems 19(1) 71-98.

Kakabadse, A., N. Kakabadse. 2002. Trends in outsourcing: Contrasting USA and Europe. European Management Journal 20189 198.

Kauffman, R. J., C. H. Kriebel (Eds.). 1988. Modeling and measuring the business value of information technologies. ICIT Press, Washington, DC.

Kekre, S., K. Srinivasan. 1990. Broader product line: A necessity to achieve success? Management Science 36(10) 1216-1231.

Ketokivi, M. 2006. Elaborating the contingency theory of organizations: The case of manufacturing flexibility strategies. Production and Operations Management 15(2) 215-228.

Kleindorfer, P. R., G. H. Saad. 2005. Managing disruption risks in supply chains. Production and Operations Management 14(1) 5368.

Kogut, B., U. Zander. 1996. What do firms do? Coordination, identity and learning. Organization Science 7(5) 502-518.

Kouvelis, P., C. Chambers, H. Wang. 2006. Supply chain management research and production and operations management: Review, trends, and opportunities. Production and Operations Management 15(3) 449-469.

Lacity, M. C., L. P. Willcocks, D. F. Feeny. 1995. IT outsourcing: Maximizing flexibility and control. Harvard Business Review 73(3) 84-93.

Lucas, H. C. 1993. The business value of information technology: a historical perspective and thoughts for future research in Strategic information technology management: perspectives on organizational growth and competitive advantage, R. D. Banker, R. J. Kauffman, and M. A. Mahmood (eds.), Idea Group Publishing, Harrisburg, Pennsylvania, 1993 359-374.

Malone, T. W., J. Yates, R. I. Benjamin. 1987. Electronic markets and electronic hierarchies. Communications of the ACM 30(6) 484497.

McAfee, A. 2002. The impact of enterprise information technology adoption on operational performance: An empirical investigation Production and Operations Management 11(1) 33-53.

Miles, R., C. C. Snow, A. D. Meyer, H. J. Coleman. 1978. Organizational strategy, structure, and process. Academy of Management Review 3(3) 546-562.

Mithas, S., D. Almirall, M. S. Krishnan. 2006a. Do CRM systems cause one-to-one marketing effectiveness? Statistical Science 21(2) 223-233.

Mithas, S., I. R. Bardhan, J. M. Goh. 2006b. Achieving revenue growth and cost reduction ambidexterity through information technology: Theory and evidence in Working Paper, R. H. Smith School of Business, University of Maryland, College Park, Maryland.

Mithas, S., J. L. Jones. 2007. Do auction parameters affect buyer surplus in e-auctions for procurement? Production and Operations Management 16(4) 455-470.

Mithas, S., M. S. Krishnan, C. Fornell. 2005a. Why do customer 
Bardhan, Mithas, and Lin: Performance Impacts in U.S. Manufacturing Plants Production and Operations Management 16(6), pp. 747-762, () 2007 Production and Operations Management Society

relationship management applications affect customer satisfaction? Journal of Marketing 69(4) 201-209.

Mithas, S., N. Ramasubbu, M. S. Krishnan, V. Sambamurthy. 2005b. Information technology infrastructure capability and firm performance: An empirical analysis in Working Paper, Ross School of Business, University of Michigan, Ann Arbor.

Mithas, S., J. Whitaker. 2007. Is the world flat or spiky? Information intensity, skills and global service disaggregation. Information Systems Research 18(3)237-259.

Mukhopadhyay, T., S. Kekre. 2002. Strategic and operational benefits of electronic integration in B2B procurement process. Management Science 48(10) 1301-1313.

Murthi, B. P. S., K. Srinivasan, G. Kalyanaram. 1996. Controlling for observed and unobserved managerial skills in determining first-mover market share advantages. Journal of Marketing Research 33(August) 329-336.

Narasimhan, R., A. Das. 1999. An empirical investigation of the contribution of strategic sourcing to manufacturing flexibilities and performance. Decision Sciences 30(3) 683-718.

Niezen, C., W. Weller. 2006. Procurement as strategy. Harvard Business Review 84(9) 24-25.

Porter, M. E. 1996. What is strategy? Harvard Business Review NovDec 61-78.

Quinn, J. B. 1994. Intelligent enterprise. Free Press, New York.

Quinn, J. B., F. G. Hilmer. 1994. Strategic outsourcing. Sloan Management Review 35(4) 43-55.

Rai, A., R. Patnayakuni, N. Patnayakuni. 1997. Technology investment and business performance. Communications of the ACM 40(7) 89-97.

Rai, A., R. Patnayakuni, N. Seth. 2006. Firm performance impacts of digitally-enabled supply chain integration capabilities MIS Quarterly 30(2) 225-246.

Ramasubbu, N., S. Mithas, M. S. Krishnan. 2008. High tech, high touch: The effect of employee skills and customer heterogeneity on customer satisfaction with enterprise system support services Decision Support Systems. 44(2) 509-523.

Rosenzweig, E. D., A. V. Roth. 2004. Towards a theory of competitive progression: Evidence from high-tech manufacturing. Production and Operations Management 13(4) 354-368.

Ross, J. W., C. M. Beath, D. L. Goodhue. 1996. Develop long-term competitiveness through information technology assets. Sloan Management Review 38(1) 31-42.
Rubin, D. B., R. P. Waterman. 2006. Estimating the causal effects of marketing interventions using propensity score methodology. Statistical Science 21(2) 206-222.

Rust, R. T., C. Moorman, P. R. Dickson. 2002. Getting return on quality: Revenue expansion, cost reduction, or both? Journal of Marketing 66(4) 7-24.

Sambamurthy, V., A. Bharadwaj, V. Grover. 2003. Shaping agility through digital options: Reconceptualizing the role of information technology in contemporary firms. MIS Quarterly 27(2) 237-263.

Srinivasan, K., S. Kekre, T. Mukhopadhyay. 1994. Impact of electronic data interchange technology on JIT shipments. Management Science 40(10) 1291-1304.

Tafti, A., S. Mithas, M. S. Krishnan. 2007. Information technology and the autonomy-control duality: Toward a theory. Information Technology and Management 8(2) 147-166.

The Economist. 2006. Survey: Logistics. June 15, 2006.

Thurm, S. 2007. Behind outsourcing: Promise and pitfalls in Wall Street Journal (February 26, 2007), Washington, DC, p. B3.

U.S. Census Bureau. 2002. Statistical abstract of the United States: 2002. United States Census Bureau, Washington, DC.

van Heerde, H. J., M. G. Deimpe, W. P. Putsis Jr. 2005. Marketing models and the Lucas critique. Journal of Marketing Research XLII (February) 15-21.

Wade, M., J. Hulland. 2004. Review-The resource based view and information systems research: Review, extension, and suggestions for future research. MIS Q 28(1) 107-142.

Wagner, D. 2006. Success factors in outsourcing service jobs: Which jobs are good candidates for global disaggregation? (available at http://sloanreview.mit.edu/smr/issue/2006/fall/03/). MIT Sloan Management Review 48(1) 7.

Whitaker, J., S. Mithas, M. S. Krishnan. 2007. A field study of RFID deployment and return expectations. Production and Operations Management 16(5) 599-612.

Zaheer, A., S. Zaheer. 1997. Catching the wave: Alertness, responsiveness, and market influence in global electronic networks. Management Science 43(11) 1493-1509.

Zhu, K., K. L. Kraemer. 2002. e-Commerce metrics for net-enhanced organizations: Assessing the value of e-Commerce to firm performance in the manufacturing sector. Information Systems Research 13(3) 275-295. 